\title{
A Cross-cultural Comparative Study of Requests Made in Chinese by South Korean and French Learners*
}

\author{
Jieqiong Ying \\ Zhejiang International Studies University, Zhejiang, China \\ Gang Hong \\ Zhejiang International Studies University, Zhejiang, China
}

\begin{abstract}
This study aims to examine the differences of pragmatic strategies of requests made in Chinese by South Korean and French learners, in comparison to those made by Chinese native speakers (CNS). Using a Discourse Completion Test (DCT) questionnaire as the research tool, 20 Chinese, 20 French students and 20 South Korean students from the Shanghai International Studies University (SISU) were randomly selected to complete the questionnaire. The response data from the Chinese student questionnaires were used as the baseline data for comparison as well as generating a modified coding scheme. The results show that Chinese speakers and South Korean learners tend to be more direct by using "query preparatory" and "mood derivable" as head acts, while French learners tend to be indirect by primarily using "query preparatory." In terms of sociopragmatics, the results show that Korean learners and Chinese tend to be hierarchical and collectivistic, while French students are prone to be egalitarian and individualistic. L2 transfer, inductive/deductive mindset, unfamiliarity, and varied perceptions of politeness could be possible reasons for the differences in request strategies. This study concludes with suggestions for future research and pedagogy.
\end{abstract}

Index Terms - interlanguage pragmatics, speech act, requests, pragmalinguistics, sociopragmatics

\section{INTRODUCTION}

Interlanguage Pragmatics (ILP) studies focus exclusively on comparing non-native speakers' production and comprehension of speech acts (Schauer 2009). In ILP, the request speech act, containing an illocutionary act, remains as one of the most widely examined speech acts, and it is regarded as one of the most face-threatening speech acts (Sabzalipour et al. 2017). Many studies have explored request speech acts across cultures (Economidou-Kogetsidis 2008; Kahraman \& Akkus 2007; Koc 2011; Kotorova 2015; Rasouli Khorshidi 2013). However, only a few studies on requests were focused on Chinese (Chen 2015; Gao 1999; Hong 1996; Lee-wong 1994). Moreover, all these studies explored requests made by learners of same cultural background. Thus, this study examines the request strategies of Chinese used by L2 learners of varying cultural backgrounds, aiming to explore different pragmatic strategies of Chinese requests and the effects of varying cross-cultural and cross-linguistic scenarios.

Appropriate realization of request speech act calls for speaker's perception of the politeness in that particular community. However, the transfer of pragmatic strategies from L1 to L2 seems unavoidable, which results in variations of L2 learners' speech act performance of different speech communities, especially concerning the level of directness of their request realization (Phindane 2017). Non-native speakers, such as learners from South Korea and France, are likely to encounter problems in a particular speech act realization in Chinese. Inappropriate use of words and phrases in speech acts tends to evoke unpleasant impression in Chinese native speakers. However, to date, there is no study focusing on requests made in Chinese by learners from South Korea and France.

\section{LITERATURE REVIEW}

\section{A. Chinese Requests}

Many studies have been carried out to examine requests in various languages and cultures, while a few studies have investigated requests made in Chinese language. Hong (1996) examined the use of linguistic politeness of requests made by Chinese. Data was collected with production questionnaires, and the findings revealed that the choice of linguistic usage heavily depended on social distance and power relations between speakers and hearers. Lee-wong (1994) conducted a study to investigate requests made by Chinese native speakers (CNS) from Mainland China. Using adopting interview and questionnaire as data collection methods, the results show that CNS preferred to use direct

\footnotetext{
* Grant: This article is supported by a grant from Humanity and Social Science Youth Foundation of Ministry of Education of China (Grant No.19YJC740108); from Regular Social Science Foundation of Hangzhou (Grant No. M19JC033)
} 
strategies and internal modifications over indirect ones and external modifications, which reflected the phenomenon that Chinese culture attaches much importance to sincerity and solidarity. Wang (2014) explored the request strategies based on corpora of contemporary Chinese television dramas videos. The study shows that mood derivable, query preparatory, and hedged performatives are the most used request strategies, and Chinese tend to be more straightforward in real life. However, Zhang's (1995) study of Chinese requests via DCT produced inconsistent results with Lee-won's and Wang's. Zhang argues that Chinese requests preferred indirect strategies rather than direct ones.

Few comparative studies have been conducted on requests in Chinese made by L2 learners, and the results were inconsistent. Rue and Zhang (2008) conducted a comparative analysis of requests in Mandarin Chinese and South Korean, using naturally occurring conversational dialogue as the main data source. Adopting the coding scheme of Cross-cultural Study of Speech Act Realization Patterns (CCSARP), they found that CNS were more indirect in producing requests than their South Korean counterparts, and the former preferred more indirect head acts, such as interrogative and imperative, than the latter. Findings were inconsistent when comparing with pragmatic strategies of requests made by L2 learners from Western cultures. Huang (1996) examined request strategies between Taiwanese Mandarin and American English. According to the analysis of the Discourse Completion Test (DCT), the study revealed that Taiwanese preferred direct strategies and used more alterters and supportive moves than American English speakers. Li \& Jiang (2019) examined requests between Australian learners of Chinese and CNS by adopting a written DCT, and the results indicate that both learners and CNS preferred to use indirect strategies. Thus, this study examines pragmatic strategies of requests made by L2 learners from both Eastern and Western cultures to better undersand their different preference of requestive strategies in Chinese.

\section{B. Pragmalinguistics and Sociopragmatics}

Pragmatic competence is regarded as an essential component of foreign or sencond language proficiency. It refers to language learners' ability to choose appropriate linguistic forms in a variety of contexts (Tuguchi et al. 2016). It requires learners' access to the knowledge of linguistic forms and functions as well as the situational factors of certain contexts, while making a particuluar speech act. More specifically, pragmatic competence consists of pragmalinguistic and sociopragmatic knowledge. The former emphasizes linguistic structures for utterances in a language, and describes how we must use them in a correct way for a language; the latter emphasizes the sociocultural respects of social interaction, and focuses on situational factors, such as power, social distance, gender, etc. (Leech 1983; Thomas 1983). Thus, both pragmalinguistic and sociopragmatic knowledge are important for learners' interpretation and performance of request speech acts in Chinese. The operating definitions of pragmalinguistic and sociopragmatic knowledge in this study are as follows: pragmalinguistic knowledge refers to the type of semantic formulae used in varying contexts; and sociopragmatic knowledge refers to request strategies, i.e. the directness level of Head Act (HA) in relation to power and social distance.

This study aims to investigate both South Korean and French learners' pragmalinguistic and sociopragmatic knowledge of Chinese requests to understand the different usage tendency of semantic formulae in requests, which can in turn offer pedagogical implications for classroom instructions, and also raise L2 learners' awareness of their own pragmatic strategies in Chinese. The research questions are posed as follows:

1. What are the pragmalinguisitic differences in requests used by South Korean and French learners, in comparison to those of CNS?

2. What are the sociopragmatic differences in requests used by South Korean and French learners, in comparison to those of CNS?

3. What reasons account for the above differences?

\section{RESEARCH DESIGN}

This section elaborates participant selection, describes the instruments, illustrates the data collection process, and demonstrates the modified coding scheme and the analytical protocol.

\section{A. Participants}

The participants in this investigation included 60 students from the Shanghai International Studies University (SISU). Among them were 20 Chinese students, all of which were sophomores and majored in international education, with an average age of 21. There are 20 South Korean learners of Chinese (KLC) and 20 French learners of Chinese (FLC) chosen respectively as participants, who studied at SISU, with an average age of 20.5. In order to ensure the reliability of the data, the selection requirements were: 1) they had just arrived at SISU in September of 2015, and they had passed the third level of the Chinese Proficiency Test (Hanyu Shuiping Kaoshi, aka HSK); 2) they have grew up and lived in their home countries based on their background information.

We received the name list of Chinese, French, and South Korean students, and chose the participants randomly from different classes at the beginning of the semester in September 2015. With assistance from the dean of the School of Chinese Studies and Exchange at SISU, 20 KLC and 20 FLC were eventually chosen from Language Course Programs. Cross-sectional data was collected to compare their pragmatic strategies and linguistic forms from the cross-cultural perspective. 


\section{B. Instruments}

DCT was employed as the research instrument in this study. If carefully designed, it is an effective way to examine speaker's pragmalinguistic knowledge of semantic formulae and the pragmatic strategies they used to achieve their intention in speech acts, and to assess their sociopragmatic knowledge of the situational factors under which certain strategies and linguistic forms are proper (Kasper 2000; Hong 2005). This study aims to find the differences in requests made by KLC and FLC in terms of pragmalinguistic and sociopragmatic aspects. Thus, the written DCT was chosen as an appropriate instrument for the study. Some informal interviews were also carried out for accurate interpretation of learners' sociopragmatic knowledge.

Imposition was controlled for the scenario design in DCT focusing on systemic variations of two situational factors: power and distance, since the choice of linguistic usage in Chinese requests depended heavily on social distance and power relations between the speaker and the hearer (Hong 1996). Eventually, six combinations of these two situational variables were formed: [D-, P+], [D-, P=], [D-, P-], [D+, P+], [D+, P=] and [D+, P-] (Table 1).

TABLE 1

SOCIAL VARIABLES EMBEDDED IN SCENARIOS

\begin{tabular}{ccc}
\hline \hline Distance & Referent in questionnaire & \multicolumn{2}{c}{ Relative social ranking with reference to } \\
speaker & Higher [P+] \\
\hline Unfamiliar & University administrator & Equal $[\mathrm{P}=]$ \\
{$[\mathrm{D}+]$} & Stranger & Lower $[\mathrm{P}-]$ \\
Familiar & Group member & Higher $[\mathrm{P}+]$ \\
{$[\mathrm{D}-]$} & Professor & Equal $[\mathrm{P}=]$ \\
& Good friend & Lower $[\mathrm{P}-]$
\end{tabular}

Twelve scenarios were designed with two situations for each variable combination (see Appendix A). In the scenario design, the following issues were considered. First, the scenarios should frequently occur in the learners' daily life. Second, all scenarios should be valid to grasp the differences and features of the pragmatic strategies of the two selected cultures.

\section{Data Collection}

Data collection with KLC and FLC took place in September 2015. Three instructors distributed questionnaires to students in class. In order to capture their real response, participants were required to write down what they would really say in such situations without hesitation. The whole data collection took roughly 30 minutes.

As for the Chinese baseline data collection, one of the researchers worked as a part-time lecturer at SISU, so the 20 Chinese questionnaires were collected at the end of the class in September 2015, and all Chinese students completed the questionnaire in about 15 minutes.

\section{Coding Scheme}

Semantic formulae "represent the means by which a particular speech act is accomplished, such as a reason, an explanation, or an alternative" (Beebe et al. 1990). The examination of semantic formulae has been conducted extensively in request speech acts (Blum-Kulka \& Olshtain 1984; Byon 2004; Cohen \& Shively 2007). As for the coding scheme of request speech acts, we referenced previous studies in English, mainly of Blum-Kulka et al. (1989) in CCSARP. According to their manual, a request speech act could be divided into three moves: openers, head act (HA), and supportive moves (SM) or external modifications (EM). The HA of a request is categorized as Direct (D), Conventional Indirect (CID) or Non-Conventional Indirect (NCID), which are further grouped into 9 subcategories according to the level of the directness (Blum-Kulka et al. 1989).

In order to examine whether this coding scheme was appropriate for Chinese requests, the data of 20 CNS were collected and analyzed. Adjustments to the coding scheme of CSSARP were made, which are demonstrated below.

Mood derivable: The grammatical mood of the head act determines by its illocutionary force as a request, e.g. 借我 拷一下课件！ (Lend the courseware to me!)

Performative: The speaker conveys the implied means by using a specific verb, making the request an order or a plea, e.g. 我恳请您能同意延迟交作业的时间 ? (I beg you to agree on postponing the deadline of submission.)

Want statement: This formula reveals the speaker's desire, concern or want that the utterance is made, e.g. 我想换寝 室 (I want to change a dormitory).

Suggestive formulae: The speaker uses suggest conveying the illocutionary intent, with an open answer to the question, e.g. 帮我们组做课件，怎么样？ (How about helping us make a courseware?)

"Query preparatory (1)": the speaker asks the feasibility of the request by a preparatory question, asking the hearer's 
ability, willingness, or possibility as conventionalized in the given language, e.g. 能帮我们拍张照片吗? (Can you take a photo of us?)

"Query preparatory (2)": the referential meaning of the utterance is the same as the query preparatory (1). However, its social meanings such as formality, politeness, power, and solidarity are encoded differently because of the different syntactic structure. The general syntactic structure is "want statement/statement + short question formulae", and the answer to it is always closed, e.g. 你来负责做 PPT， 好不好? (Could you take charge of PPT design?)

Hint: The intended meaning of the request is not formed explicitly. The speaker offers strong clues to make the hearer understood, e.g. 有多余的笔吗? (Do you have an extra pen? Intent: asking the hearer to lend a pen to the speaker.)

Regarding EM, in addition to "preparatory", "cost minimizer", "promise of reward", "apology", "humbling oneself", "self-introduction", "gratitude", "begging for help", "sweetener", "disarmer", and "asking the hearer's opinion", the type of "ending words" is added to EM, and "grounder" is divided into two groups, which is described as follows:

"Ending words": the speaker expresses remorse for possible burden the request would cause to the hearer by saying some polite words, e.g. Bu-hao-yi-si! (不好意思, I am sorry), Xin-ku-ni-le! (辛苦你了, That's very kind of you).

" $\mathrm{G}+\mathrm{H}$ ": a grounder (reasons, or justifications for his or her request) is first uttered, and then a request is made, e.g. 我校园卡丢了, 想要补办一张。 (I lost my student identity card. And I want to get a new one.)

“H + G”: a request is first made, and then a grounder is presented, e.g. 你能不能把上课的内容录音发我? 今天我

肚子痛没去上课 (Could you send me the audio recorder of the course? My stomach aches, so I didn't go to the class).

Regarding openers, Byon (2004) identifies the following formulae for openers: "title", "name", "greeting" and "attention-getter". Based on the data collected in this study, two types of formulae are added as openers: "kinship terminology" and "popular alerters".

"Kinship terminology": an element in the form of "kinship terminology" whose function is to alert hearer's attention, e.g. a-yi (阿姨, aunt), xiong-di (兄弟, brother).

"Popular alerter": an element in the form of "popular alerter" whose function is to alert hearer's attention, e.g. Mei-nv (美女, beauty), shuai-ge (帅哥, handsome man), qin-ai-de (亲爱的, dear).

\section{E. Data Analysis}

In response to the research questions, the data collected through the DCT questionnaires were carefully marked, coded, and double-checked. The questionnaires with incorrect responses or unanswered questions were regarded as invalid. The steps of the analysis were as follows: 1) From the pragmalinguistic perspective, we examined and counted the number of semantic formulae for openers, HA and EM by FLC and KLC, in comparison to that of CNS; and Chi-square test was also employed to examine the significant differences between FLC, KLC and CNS; 2) From the sociopragmatic perspective, we mainly focused on level of directness, i.e. semantic formulae of the HA, based on variations of the power and distance; 3 ) we figured out the main reasons for the differences in semantic formulae that were used by learners according to the analysis of DCT data.

\section{RESULTS AND DISCUSSION}

This section displays the quantitative data to illustrate the different use of semantic formulae for openers, HA and EM between KLC, FLC and CNS. Pragmalinguistic differences and sociopragmatic differences are respectively described.

\section{A. Differences in Semantic Formulae of Request Strategies}

1. Pragmalinguistic differences

In general, Chinese speakers employed more formulae for openers (266) than FLC (168) and KLC (175). And they used only one HA in each request behavior, resulting with 240 in total. However, both French and Korean students employed more HAs than Chinese, the total number were 241 and 259 respectively. KLC had a strong tendency to use EM to modify HA. They employed 239 EM, which were more than those of Chinese (229) and French users (213).

\section{Differences in formulae for openers}

Table 2 shows that the total number of semantic formulae for openers by foreign learners was less than that of CNS. The three most popular formulae for openers of CNS were "title" (30.5\%), "greeting" (22.6\%), and "name" (18.0\%). As for KLC, the three most favored formulae were: "title" (24.6\%), "attention-getter" $(22.9 \%)$, and "greeting" $(18.9 \%)$. And FLC's were "greeting" (38.7\%), "attention-getter" (22.0\%) and "title" (17.9\%). 
TABLE 2

SEMANTIC FORMUlaE OF OPENERS FOR THE THREE CULTURAL GROUPS

\begin{tabular}{|c|c|c|c|c|}
\hline & & CNS & KLC & FLC \\
\hline \multirow[t]{2}{*}{ Title } & Title & $(30.5) 81$ & (24.6) 43 & (17.9) 30 \\
\hline & Title+PM & (12.0) 32 & $(5.1) 9$ & (10.1) 17 \\
\hline \multicolumn{2}{|c|}{ Name } & (18.0) 48 & (13.1) 23 & $(5.3) 9$ \\
\hline \multicolumn{2}{|c|}{ Greeting } & $(22.6) 60$ & (18.9) 33 & $(38.7) 65$ \\
\hline \multicolumn{2}{|c|}{ Attention-getter } & (5.3) 14 & (22.9) 40 & (22.0) 37 \\
\hline \multicolumn{2}{|c|}{ Kinship terminology } & (3.4) 9 & (11.4) 20 & $(6.0) 10$ \\
\hline \multicolumn{2}{|c|}{ Popular alerters } & $(8.2) 22$ & (4.0) 7 & 0 \\
\hline \multicolumn{2}{|c|}{ Total (openers) } & (100) 266 & (100) 175 & (100) 168 \\
\hline
\end{tabular}

(Data partially cited from Ying 2019)

SPSS was employed to examine the significant difference by $\log$-likelihood ratio. $\mathrm{P}<0.05$ is regarded as significant difference. Both KLC and FLC differed significantly from CNS in the use of "title+PM" ( $\mathrm{P}=0.000 ; \mathrm{P}=0.000)$ "attention-getter" ( $\mathrm{P}=0.049 ; \mathrm{P}=0.000)$ and "popular alerter" $(\mathrm{P}=0.007 ; \mathrm{P}=0.000)$. Learners did not use "title+PM", such as “lao-shi nin-hao" (老师您好, hello teacher) as much as CNS. As for "attention-getter", the KLC tended to use “bu-hao-yi-si” (不好意思, excuse me), “dui-bu-qi” (对不起, pardon), and “da-rao-yi-xia” (打扰一下, excuse me) to address strangers or administrators. However, FLC were prone to use “hei” (嘿, hey), “dui-bu-qi” (对不起, pardon) and “bu-hao-yi-si" (不好意思, excuse me) to address others in various situations. And all learners seldom employed popular alterters such as “qin-ai-de" (亲爱的, dear), which has been a newly corned popular words among Chinese youth in recent years.

Moreover, the use of openers by French subjects differed from that of Chinese more significantly than their Korean counterparts, since FLC with 5 indicators and KLC with 4 indicators differed from CNS significantly.

\section{Differences in strategy types for head act}

As mentioned above, the learners produced more than 240 valid HAs. The three most popular HA formulae of CNS were "QP (1)" (49.2\%), "mood drivable" (18.3\%), and "QP (2)" (15.4\%). As for KLC, the three most favored formulae were the same as that of Chinese subjects, but the proportion differed: "QP (1)" (50.2\%), "mood drivable" (21.6\%), and "QP (2)" (18.9\%). And FLC were "QP (1)" (67.2\%), "mood drivable" (8.3\%), and "want statement" (7.1\%) (see Table $3)$.

TABLE 3

STRATEGy TyPes OF HA For THE THREE CUltural GROUPS

\begin{tabular}{|c|c|c|c|}
\hline & CNS & KLC & FLC \\
\hline Mood derivable & (18.3) 44 & $(21.6) 56$ & (8.3) 20 \\
\hline Performative & $(2.5) 6$ & (1.2) 3 & (4.6) 11 \\
\hline Want statement & (10.8) 26 & (8.9) 23 & (7.1) 17 \\
\hline Suggestory formulae & (2.1) 5 & 0 & $(2.5) 6$ \\
\hline Query $\quad \mathrm{QP}(1)$ & (49.2) 118 & (50.2) 130 & (67.2) 162 \\
\hline preparatory & (15.4) 37 & (15.4) 40 & (6.2) 15 \\
\hline Strong hint & (1.7) 4 & (1.9) 5 & (3.3) 8 \\
\hline Mild hint & 0 & $(0.8) 2$ & $(0.8) 2$ \\
\hline Total (HA) & (100) 240 & (100) 259 & (100) 241 \\
\hline
\end{tabular}

(Data partially cited from Ying 2019)

Only two indicators, i.e. "suggestory formula" $(\mathrm{P}=0.008)$ and "QP (2)" ( $\mathrm{P}=0.003)$, showed significant difference between KLC and CNS, while three indicators used by FCL, i.e. "mood derivable" $(\mathrm{P}=0.023)$, "want statement" $(\mathrm{P}=0.018)$, and " $\mathrm{QP}(2)$ " $(\mathrm{P}=0.001)$, were significant different from that of CNS. All learners preferred "query preparatory", but they were all distinct from CNS for "QP (2)". KLC preferred to use “..., hao-bu-hao" (..., 好不好; ..., is it ok) or “..., ke-bu-ke-yi” (..., 可不可以; ..., is it ok) rather than "neng-bu-neng.....?” (能不能...; could you...). In contrast, FLC were prone to use QP (1) far more than QP (2). CNS and KLC often used direct request strategies towards roommates or good friends, While FLC employed far less "mood derivable" and "want statement", and regarded as the most indirect ones, which confirmed Mulken's (1996) results.

\section{Differences in formulae for external modifications}

As for EM (see Table 4), the most popular formulae among the three cultural groups (in the order of CNS, KLC, and FLC) were "grounder" (58.0\%; 55.5\%; 60.1\%), "preparatory" (11.4\%; 13.4\%; 12.7\%), "gratitude" $(11.4 \% ; 6.7 \% ; 12.2 \%)$, and "sweetener" $(8.7 \% ; 7.1 \% ; 4.7 \%)$. As for "grounder", FLC differed from CNS significantly ( $\mathrm{P}=0.042)$, who tended to use much more "H+G" $(37.6 \%)$ than Chinese (19.6\%) and KLC (12.2\%). Moreover, the types of formulae CNS and KLC used were more diverse, while FLC tended to be more monotonous. And some types of formulae had not been

\footnotetext{
${ }^{1}$ Data are partially cited from the published $\mathrm{PhD}$ thesis written by the first author.
} 
covered by FLC, such as "promise of reward", "disarmer", and "ending words".

TABLE 4

SEMANTIC FORMULAE OF EM FOR THE THREE CULTURAL GROUPS

\begin{tabular}{|c|c|c|c|c|}
\hline & & CNS & KLC & FLC \\
\hline \multicolumn{2}{|l|}{ Preparator } & (11.4) 25 & $(13.4) 32$ & (12.7) 27 \\
\hline \multirow[t]{2}{*}{ Grounder } & $\mathrm{G}+\mathrm{H}$ & (38.4) 84 & (43.3) 103 & (22.5) 48 \\
\hline & $\mathrm{H}+\mathrm{G}$ & (19.6) 43 & $(12.2) 29$ & (37.6) 80 \\
\hline \multicolumn{2}{|c|}{ Cost minimizer } & $(2.7) 6$ & $(2.5) 6$ & $(0.5) 1$ \\
\hline \multicolumn{2}{|c|}{ Promise of reward } & (0.9) 2 & (4.2) 10 & 0 \\
\hline \multicolumn{2}{|c|}{ Apology } & (1.8) 4 & $(0.5) 1$ & (4.2) 9 \\
\hline \multicolumn{2}{|c|}{ Humbling oneself } & $(0.5) 1$ & $(0.5) 1$ & 0 \\
\hline \multicolumn{2}{|c|}{ Self introduction } & $(0.9) 2$ & (4.6) 11 & (1.4) 3 \\
\hline \multicolumn{2}{|c|}{ Gratitude } & (11.4) 25 & (6.7) 16 & (12.2) 26 \\
\hline \multicolumn{2}{|c|}{ Begging for help } & $(1.8) 4$ & $(0.4) 1$ & $(0.9) 2$ \\
\hline \multicolumn{2}{|c|}{ Sweetener } & (8.7) 19 & (7.1) 17 & (4.7) 10 \\
\hline \multicolumn{2}{|c|}{ Disarmer } & $(0.5) 1$ & 0 & 0 \\
\hline \multicolumn{2}{|c|}{ Asking for the hearer's opinion } & $(0.5) 1$ & $(0.8) 2$ & (3.3) 7 \\
\hline \multicolumn{2}{|c|}{ Ending words } & $(0.9) 2$ & (3.8) 9 & 0 \\
\hline \multicolumn{2}{|c|}{ Total (SM) } & (100) 219 & 238 (100) & 213 \\
\hline
\end{tabular}

(Data partially cited from Ying 2019)

Interestingly, the use of EM by KLC was more different from CNS than FLC from CNS. In general, KLC tended to overuse those formulae in requests, which resulted in the significant difference of some types of the formulae, such as "promise of reward" ( $\mathrm{P}=0.028)$ and "self-introduction" $(\mathrm{P}=0.012)$, while French subjects were prone to use less, which caused the significant difference of some type of EM, namely "cost minimizer" $(\mathrm{P}=0.030)$ and "sweetener" $(\mathrm{P}=0.017)$. The reason might be that KLC had a better command of linguistic forms, and attempted to show their language proficiency, which led to the overuse of EM.

\begin{tabular}{|c|c|c|c|c|c|c|c|c|c|c|}
\hline \multicolumn{2}{|c|}{ Scenarios } & \multicolumn{3}{|c|}{ Administrator $[\mathrm{D}+, \mathrm{P}+]$} & \multicolumn{3}{|c|}{ Stranger $[\mathrm{D}+, \mathbf{P}=]$} & \multicolumn{3}{|c|}{ Group member $[\mathrm{D}+$, P- $]$} \\
\hline & & CNS & KLC & FLC & CNS & KLC & FLC & CNS & KLC & FLC \\
\hline Moo & erivable & $(12.5) 5$ & $(21.7) 10$ & (10) 4 & (2.5) 1 & $(6.8) 3$ & (2.6) 1 & (25) 10 & $(23.3) 10$ & $(7.9) 3$ \\
\hline Perf & ative & $(2.5) 1$ & $(2.2) 1$ & $(7.5) 3$ & 0 & $(2.3) 1$ & 0 & $(5.0) 2$ & 0 & $(15.8) 6$ \\
\hline Wan & atement & (42.5) 17 & (32.6) 15 & $(22.5) 9$ & $(2.5) 1$ & $(2.3) 1$ & $(7.6) 3$ & 0 & $(2.3) 1$ & 0 \\
\hline $\begin{array}{l}\text { Sugg } \\
\text { form }\end{array}$ & & $(2.5) 1$ & 0 & 0 & 0 & 0 & 0 & (10) 4 & 0 & $(15.8) 6$ \\
\hline \multirow[t]{2}{*}{ QP } & $\mathrm{QP}(1)$ & $(32.5) 13$ & $(37.0) 17$ & (40) 16 & $(87.5) 35$ & $(72.7) 32$ & $(87.2) 34$ & (30) 12 & (41.9) 18 & $(39.5) 15$ \\
\hline & $\mathrm{QP}(2)$ & $(7.5) 3$ & $(6.5) 3$ & (15) 6 & $(7.5) 3$ & $(15.9) 7$ & $(2.6) 1$ & $\begin{array}{l}(27.5) \\
11\end{array}$ & $(18.6) 8$ & $(10.5) 4$ \\
\hline \multicolumn{2}{|c|}{ Strong hint } & 0 & 0 & (5) 2 & 0 & 0 & 0 & $(2.5) 1$ & $(9.3) 4$ & $(10.5) 4$ \\
\hline \multicolumn{2}{|c|}{ Mild hint } & 0 & 0 & 0 & 0 & 0 & 0 & 0 & $(4.6) 2$ & 0 \\
\hline \multicolumn{2}{|c|}{$(\mathrm{HA})$} & $(100) 40$ & (100) 46 & $(100) 40$ & $(100) 40$ & $(100) 44$ & (100) 39 & $\begin{array}{l}(100) \\
40\end{array}$ & (100) 43 & (100) 38 \\
\hline \multicolumn{2}{|c|}{ Scenarios } & \multicolumn{3}{|c|}{ Professor [D-, P+] } & \multicolumn{3}{|c|}{ Good friend [D-, P=] } & \multicolumn{3}{|c|}{ Roommate [D-, P-] } \\
\hline & & CNS & KLC & FLC & $\mathrm{CNS}$ & KLC & FCL & $\mathrm{CNS}$ & KLC & FLC \\
\hline \multicolumn{2}{|c|}{ Mood derivable } & $(2.5) 1$ & $(2.2) 1$ & 0 & $(23.7) 9$ & $(43.3) 16$ & $(21.4) 9$ & $(41.9) 18$ & $(37.2) 16$ & $(7.3) 3$ \\
\hline \multicolumn{2}{|c|}{ Performative } & 0 & 0 & 0 & $(2.6) 1$ & $(2.7) 1$ & (4.8) 2 & 0 & 0 & 0 \\
\hline \multicolumn{2}{|c|}{ Want statement } & $(2.5) 1$ & (13) 6 & $(9.8) 4$ & 0 & 0 & $(2.4) 1$ & 0 & 0 & 0 \\
\hline \multicolumn{2}{|c|}{$\begin{array}{l}\text { Suggestory } \\
\text { formulae }\end{array}$} & 0 & 0 & 0 & 0 & 0 & 0 & 0 & 0 & 0 \\
\hline \multirow[t]{2}{*}{ QP } & $\mathrm{QP}(1)$ & (70) 28 & (63) 29 & (82.9) 34 & $(63.2) 24$ & $(32.4) 12$ & (66.7) 28 & $(39.5) 17$ & $(51.2) 22$ & (85.4) 35 \\
\hline & $\mathrm{QP}(2)$ & $(22.5) 9$ & (19.6) 9 & $(2.4) 1$ & $(7.9) 3$ & $(21.6) 8$ & $(4.7) 2$ & $(9.3) 4$ & $(11.6) 5$ & $(2.4) 1$ \\
\hline \multicolumn{2}{|c|}{ Strong hint } & $(2.5) 1$ & (2.2) 1 & (4.9) 2 & (2.6) 1 & 0 & 0 & $(9.3) 4$ & 0 & 0 \\
\hline \multicolumn{2}{|c|}{ Mild hint } & 0 & 0 & 0 & 0 & 0 & 0 & 0 & 0 & (4.9) 2 \\
\hline \multicolumn{2}{|c|}{ (HA) } & (100) 40 & (100) 46 & $(100) 41$ & (100) 38 & (100) 37 & (100) 42 & (100) 43 & $(100) 43$ & (100) 41 \\
\hline
\end{tabular}

In summary, the formulae for openers, HA and EM that KLC employed were similar to those of Chinese, while FLC differed from CNS considerably.

2. Sociopragmatic differences

This section presents the types frequency of request strategies, i.e. directness levels of HA, by FLC, KLC, and CNS, based on variations of power and distance.

Table 5 shows that CNS obviously changed their use of request strategy types according to the variations of power and distance. In general, power worked more systematically than distance. CNS tended to use $92.5 \%$ of "QP" in professor situations, while they use $48.9 \%$ of "QP" in roommate situation. Moreover, in the hearers with lower power situations, such as [D-, P-] and [D+, P-], speakers were prone to be more direct with higher percentage of "mood derivable" $(41.9 \%, 25 \%)$. When facing with hearers with equal power, distance considerably affected their use of 
request strategies. They preferred more indirect strategies in stranger situations than in good friend situations.

As shown in Table 5, Korean subjects acted significantly similarly to the Chinese users, but differences were still observed. KLC preferred "QP (1)" (63\%) and "QP (2)" (19.6\%) in professor situations ([D+, $\mathrm{P}+])$, while they tended to employ "mood derivable" in good friend $([\mathrm{D}-, \mathrm{P}=])(43.3 \%)$, roommate ([D-, $\mathrm{P}-])(37.2 \%)$, and group member ([D+, $\mathrm{P}-\mathrm{J})(23.3 \%)$ situations without much differences. French subjects were not so sensitive to these two variables and tended to use "QP" in all situations. Apart

from "QP", they sometimes employed "performative" (15.8\%) and "suggestive formulae" (15.8\%) in group member situations and good friend situations.

Table 5 Frequency of request strategy types in relation to power and social distance

\section{B. Main Reasons for Above Differences}

This section illustrates the main reasons to account for the differences in semantic formulae used by CNS, KLC and FLC, based on the analysis of quantitative and qualitative data in terms of pragmalinguistic and sociopragmatic aspects.

1. Reasons for pragmalinguistic differences

\section{Analysis of differences in openers}

According to the analyzed data, French subjects produced 168 formulae for openers, KLC employed 175, while CNS produced 266. Unfamiliarity with the target language in different languages could explain the far less formulae for openers used by L2 learners.

CNS tended to use "title" such as "lao-shi" (老师, teacher), "tong-xue" (同学, classmate), or "greeting" such as “ni-hao"/“nin-hao" (你好/您好, how are you) and "name” for openers. However, KLC sometimes tended to use “attention getter” for openers, namely, “bu-hao-yi-si” (不好意思, excuse me), “dui-bu-qi” (对不起, pardon) and “da-rao-yi-xia” (打扰一下, excuse me). It is because Koreans tend to use “실례지만” (不好意思打扰一下, excuse me) and “죄송하지만” (对不起, sorry) to address others in Korean. Regarding FLC, "greeting” was used as the most frequent formulae, since French people tended to use "comment va tu?" (你好吗 ? How are you?), followed by “attention-getter”, namely “hei” (嘿, hey), “dui-bu-qi” (对不起, pardon), and “bu-hao-yi-si” (不好意思, excuse me). It is because the formulae, such as "hey", "pardon", and "excuse me" are frequently used to address others in conversations in French. Furthermore, Chinese users tended to employ the order of "title+ PM", such as "lao-shi nin-hao" (老师您好; teacher, how are you?), while FLC preferred to use “nin-hao or ni-hao lao-shi” (你好或您好老师 ; how are you, teacher?).

In addition to unfamiliarity, L1 transfer could be another important reason. The participants in this study were all mature language users of their mother tongue, and some of them had multilingual backgrounds. Therefore, they had developed the habit of using their first language or the frequently used one in their daily life. They had a strong tendency to unconsciously translate their L1 into the L2 context. Coulmas (1981) states that transfer occurred when L2 learners tend to translate certain norms, strategies of their first language into the targeted language to achieve a particular purpose.

\section{Analysis of differences in head act}

According to the analyzed data, the total number of semantic formulae for HA by KLC and FLC was more than that of CNS. One reason can be explained by "reduplication". Learners were prone to use two or more head acts in one scenario for clarifications or confirmation of understanding. Warga and Schölmberger (2007) point out that L2 learners overused some types of strategies to make themselves understood correctly. Examples were given as follows:

1) KLC:

Tongxue, ni shi dian-zi-xin-xi zhuan-ye de, suo-yi wo xiang qing ni zuo

同学 你是 电子信息 专业 的, 所以我想 请你做

Classmate you are electronic information major $\mathrm{Prt}^{2}$, so I want please you make

ke-jian. Ni neng-bu-neng bang-mang zuo ke-jian?

课件. 你能不能帮忙做 课件? 谢谢

courseware. you can-not-can help make courseware? thanks

"Classmate, as you major in electronic information, I want to ask you to make courseware. Could you help make courseware? Thanks."

2) FLC:

Jiao-shou, wo xiang kao-bei zhe-men ke de ke-jian, hui-qu zai hao-hao xue-xi.

教授，我想拷贝 这门课 的课件, 回去 再 好好学习

professor, I want copy this course Pos courseware, go back again good study

\footnotetext{
${ }^{2}$ Prt: Sentence final particle.
} 
Nin neng-bu-neng rang wo kao-bei zhe-men ke de ke-jian?

您能不能让我拷贝 这门课的课件

You can let me copy this course Pos courseware?

"Professor, I want to copy the courseware for this lecture, because I want to review after I go back home. Could I copy the courseware of this lecture?"

CNS, KLC, and FLC were all prone to use "QP" as head acts. However, both CNS and KLC tended to use "mood derivable" in both good friend and roommate situations, while FLC were still prone to use "QP" in these situations for L1 transfer, such as follows:

3) CNS:

xx, ni zai xue-xiao ma? Wo you ge kuai-di dao le. Bang wo qu-yi-xia bei!

$\mathrm{xx}$, 你在 学校 吗? 我 有个快递到了。帮 我取一下 呗!

$\mathrm{xx}$, you at school Prt? I have a parcel arrive Prt. Help me fetch Prt!

"xx, are you in the school? I have a parcel arrived. Help me get it, please!"

4) FLC:

xx, ni-hao. Wo de yi-ge kuai-di dao-le, dan-shi wo bu-zai. Ni ke-bu-ke-yi bang-mang

$\mathrm{xx}$, 你好。我的一个快递到了, 但是我不在。你可不可以帮忙

$\mathrm{xx}$, how are you. I Pos one parcel arrive, but I not here. you may-not-may help

qu-yi-xia?

取一下?

fetch?

"xx, how are you? I have a parcel arrived, but I am not in the school. Could you help me fetch it?"

In addition, FLC did not use "QP (2)" more than "QP (1)" mainly because of L1 transfer. Moreover, overgeneralization could be another explanation for some misuses in such formulae. L2 learners preferred to use the syntactic structure, such as ke-bu-ke-yi...? (可不可以...?, could you please...?), and they seldom used the other alternatives, such as neng-bu-neng...? (能不能...?, are you able to...?). They assumed these two phrases were synonyms. In fact, they had subtle differences in making requests, as the former one focusing on hearers' willingness and the later one on hearers' capability (Lin 2009).

\section{Analysis of differences in external modifications}

In this current study, CNS preferred to give justifications or reasons before making a request $(\mathrm{G}+\mathrm{H} 36.7 \%, \mathrm{H}+\mathrm{G}$ $18.8 \%)$, and so did $\mathrm{KLC}(\mathrm{G}+\mathrm{H} 43.1 \%, \mathrm{H}+\mathrm{G} 12.1 \%)$. However, FLC tended to give reasons after requesting $(\mathrm{G}+\mathrm{H}$ $22.5 \%, \mathrm{H}+\mathrm{G} 37.6 \%)$. E.g.

5) $\mathrm{CNS}$

xx, wo dian-nao si-ji le, ni ke-yi ba dian-nao jie wo yong yi-wan ma?

$\mathrm{xx}$, 我电脑 死机了, 你可以把电脑 借 我 用一晚吗?

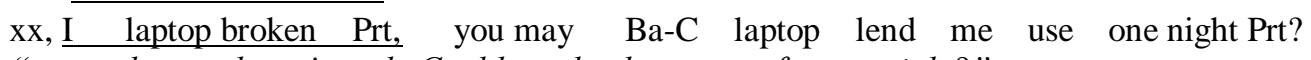

"xx, my laptop doesn't work. Could you lend me yours for one night?"

6) KLC

Didi, wode dian-nao huai le, ni ke-yi jie wo nide dian-nao ma?

弟弟, 我的电脑坏了, 你可以借我你的电脑吗?

Little brother, my laptop broken Prt, you may lend me your laptop Prt?

"Little brother, my laptop doesn't work. Could I use your laptop?"

7) FLC

Buhaoyisi, keyi yong nide diannao ma? Wo yao zuowan zuoye, keshi

不好意思, 可以用 你的电脑 吗? 我 要 做完 作业, 可是

Excuse me, may use your laptop Prt? I want complete homework, but

wode dian-nao huan le.

我的电脑 坏了。

my laptop broken Prt.

"Excuse me, could I use your laptop? I need to finish my homework, but my laptop broke down."

This could be explained by the different mindsets of Chinese and Westerners. Sapir \& Whorf Hypothesis (Hu 2011) argues that human beings' language help mold their way of thinking, and as a result, different languages may convey speakers' worldview. Liu (2014) states that when Chinese talk with others, they tend to adopt inductive pattern, while the westerners, deductive. In other words, Chinese are likely to illustrate sufficient background of the topic before coming to the point, while westerners tend to introduce the main point followed by background and reasons. Consequently, different mindsets between Chinese and Western people might account for the differences in using 
"grounder" in requests.

As mentioned above, CNS and KLC tended to use more diversified EM than French users. French subject did not use such formulae for EM for their unfamiliarity of the linguistic forms and functions of the formulae. Therefore, it is essential to teach pragmatic knowledge explicitly in the classroom.

2. Reasons for sociopragmatic differences

As shown in Table 5, the findings show that FLC tended to be most indirect. However, they only employed $85.3 \%$ of "QP" in professor scenario ([D-, P+]), while CNS used 92.5\% of "QP", and KLC used 82.6\%. Moreover, CNS were prone to use more "honorific", such as "nin-hao" in professor situation. On the contrary, CNS became more direct and employed $48.8 \%$ of "QP" and $41.9 \%$ of "mood derivable" in roommate scenario ([D-, P-]), KLC uses 62.8\% of "QP", and French employed $87.8 \%$ of "QP".

The differences could be explained by politeness phenomenon in Chinese. Social connection (Guan-xi) works as a key word for better understanding politeness phenomenon in China. In fact, it is the social network, the size of which is determined by the position or positions an individual wins or captures in the society (Xie et al. 2005). In other words, both guanxi (distance) and power are influential factors to investigate politeness phenomenon in Chinese, but power works as a more important and systematic factor than distance. Chinese tend to be a vertical society with a special emphasis on power. Chinese and Korean cultures all originated from Confucius culture, and both belong to Eastern cultures. That is why Chinese and Korean users show more respect to professors regarding power than French subjects in this study. Thus, it could be concluded that Korean and Chinese tend to be hierarchical, while French was found to be egalitarian as other westerners, which is consistent with previous studies (Byon 2004; Mulken 1996).

In addition to the hierarchy, Chinese are collectivist and group-based (Lee-wong 1994). According to Table 5, Chinese were more direct by using "mood derivable" (41.9\%) in group-member situations and so did Korean subjects (37.2\%), while French subjects only applied 7.3\%. It indicates that French are individualistic and egalitarian in comparison to Chinese. It seems that the differences in formulae produced by learners originated from deeply rooted varied perceptions of politeness across Western and Eastern cultures.

\section{CONCLUSIONS AND IMPLICATIONS}

Investigating pragmatic strategies of requests in Chinese, this study contributes to ILP in that it identifies cross-cultural and linguistic differences between South Korean, French and Chinese culture. If L2 learners were not acknowledged with Chinese request strategies and sociocultural norms, they would cause misunderstandings and multicultural communication failures. Accordingly, it is necessary to raise L2 learners' awareness of cross-cultural differences in request speech acts and facilitate the tolerance towards different characteristics of requestive patterns.

Furthermore, this study offers the following practical implications for language teaching and learning.

1) The findings suggest that teachers need to be aware of the different pragmatic features of international students from various cultural backgrounds. As mentioned in this study, learners from France and Korea had a strong tendency for certain types of semantic formulae for openers, HA, and EM. Therefore, teachers need to guide and correct learners' misuse of such formulae in requests and keep an eye on the input of pragmatic knowledge and cultural conventions to enhance learners' pragmalinguistic and sociopragmatic competence.

2) L2 learners should be aware of the pragmatic rules in the target language, under which the cultural norms regulate. Learners with a mature system of pragmatic knowledge in their native language could easily fall back on their pragmatic knowledge of L1 in learning and use of L2 (Li 2009). The results of this study could also help learners with various cultural backgrounds to be aware of the misuse of formulae or transfer in requests.

3) Textbook content should be compiled with students of different cultural backgrounds in mind and reflect the Chinese way of speaking and thinking. Future research is needed to understand various speech patterns and to apply the knowledge for the development of textbooks.

4) Teachers should be more tolerant towards the mistakes made by $L 2$ learners from cultural backgrounds that are far from Chinese culture and lay the same stress on their pragmalinguistic and sociopragmatic competence. To those learners from a cultural background similar to Chinese culture, teachers should mainly focus on their linguistic aspects since they could better understand Chinese ideology, cultural norms, and conventions.

The limitations of this study mainly lies in three aspects: 1) the result of the limited number of participants might not translate to a wider scenario; 2) comprehensive interview data should be added to enhance the validity of the study, when analyzing the reasons for the differences in formulae produced by L2 learners; 3) DCT was used to capture L2 learners' request strategies, which was questioned for failing to generate real data from natural settings. Future research should target to collect naturally occurring data of speech acts to validate the DCT elicited data to reinforce the reliability of the result. Moreover, this study can be repeated to examine whether the same results can be captured in other languages, and other speech acts such as apologies, refuse, compliments, etc.

\section{APPENDIX: DCT QUESTIONNAIRE}

1. You found your student identity card missing. You've looked everywhere for it, but still couldn't find it. You're going to the Foreign Affair Office to report the loss and apply for a new one. What would you ask? 
2. You went to visit your friend who lives in the dormitory in another university. When you came to his/her university, you couldn't find the location of the dormitory. You see a student coming towards you at that moment, and you want to ask him for directions. What would you ask?

3. This semester you've chosen an optional course. Accordingly, you're not familiar with others at the beginning of the semester. The teacher divided students into groups and asked groups to give presentations in turn. Since you were elected as group leader, it's your job to assign tasks to each group member. One of your group members majors in computer science. Now you ask him to design PowerPoint slides for the group presentation. What would you ask?

4. You're interested in the course of intercultural communication lectured by Professor Jin. You've asked him some questions about intercultural communication before, so you're familiar with each other. When the class is over, you want to copy the PowerPoint slides for after-class reviewing. What would you ask?

5. Your parcel has arrived. The messenger called you to fetch it before 17:00, but you were not there and couldn't return on time. So you want to call your good friend (Xiuming Jin) and ask him to get the parcel for you. What would you ask?

6. You roommate is the younger sister/brother of your friend. When you were doing your homework on the laptop, your laptop crashed and didn't work anymore. But you are supposed to hand in your homework tomorrow. You are going to ask your roommate to lend you his/her laptop. What would you ask?

7. You roommate stays up late almost every night. She usually turns up music loudly and makes telephone calls at later night sometimes, so you couldn't sleep well. You've talked with him/her several times, but he/ she has not changed much. So you decide to ask the dormitory management office to change a room for you. What would you ask?

8. Your best friend has come to China. You are showing him/her around the campus and Luxun Park. Both of you want to take pictures together. You see a strange student coming towards you. You are going to ask him for help. What would you ask?

9. This semester you've chosen a course. However, you're not familiar with others at the beginning of the semester. The teacher divided students into groups and asked groups to give presentation in turn. Since you were elected as group leader, it's your job to assign tasks to each group member. You want to ask one of the group members to take notes of your discussion. What would you ask?

10. You're supposed to hand in the homework of Chinese intensive reading, but you're unable to make it on time. You want to ask the teacher to postpone the deadline. You know the course teacher, Miss Wang, very well. And you're going to talk with her about it. What would you ask?

11. Today you have a stomachache, so you couldn't go to the history class. But you like the course so much that you don't want to miss it. So you are going to ask one of your classmates who is close to you to audio record the class and send it to you. What would you ask?

12. Your roommate is your friend's younger sister/brother. You go to the lecture together. When you would like to take notes, you don't have a pen on hand. So you are going to borrow one from him/her. What would you ask?

\section{REFERENCES}

[1] Abolfathiasl, H. \& A. N. Abdullah. (2015). Pragmatic consciousness-raising activities and EFL learners' speech act performance of 'making suggestions'. Journal of Language Teaching and Research, 2, 333-342.

[2] Beebe, L. \& T. Takahashi. (1989). Do you have a bag?: Social status and partterned variation in second language acquisation. Clevedon: Multilingual Matters.

[3] Beebe, L. M., T. Takahashi \& J. Uliss-weltz. (1990). Pragmtic transfer in ESL resufals. In R. C. Scarcella, E. S. Andersen \& S. D. Krashen (Eds.), Developing communicative competence in a second langauge. New York: Newbury House, 55-71.

[4] Blum-Kulka, S. \& E. Olshtain. (1984). Requests and apologies: A cross-cultural study of speech act realization patterns (CCSARP). Applied Linguistics, 3,196-213.

[5] Blum-Kulka, S. \& J. House. (1989). Cross-cultural pragmatics: Requests and Apologies. Norwood, NJ: Alex.

[6] Brown, P. \& S. C. Levinson. (1987). Politeness: Some Universals in Language Usage. Cambridge: Cambridge University Press.

[7] Bruner, J., Roy, C. \& N. Ratner. (1982). The Beginnings of Request. New York: Garden Press.

[8] Byon, A. S. (2004). Sociopragmatic analysis of South Korean requests: Pedagogical settings. Journal of Pragmatics, 9, 1673-1704.

[9] Cohen, A. D. \& R. L. Shively. (2007). Acquisition of requests and apologies in Spanish and French: Impact of study abroad and strategy-building intervention. The Modern Language Journal, 2, 189-212.

[10] Coulmas, F. (1981). Poison to your soul. In F. Columas (Eds.), Thanks and apologies contrastively viewed. The Hague: Mouton.

[11] Chen, Y. (2015). Chinese learners' cognitive processes in writing email requests to faculty. System, 52,51-62.

[12] Economidou-Kogetsidis, M. (2008). Internal and external mitigation in interlanguage request production: The case of Greek learners of English. Journal of Politeness Research, 4, 111-138.

[13] Economidou-Kogetsidis, M. (2010). Cross-cultural and situational variation in requesting behaviour: Perceptions of social situations and strategic usage of request patterns. Journal of Pragmatics, 8, 2262-2281.

[14] Félix-Brasdefer, J. C. \& M. Hasler-Barker. (2015). Complimenting in Spanish in a short-term study abroad context. System, 48, $75-85$.

[15] Fukushima, S. (2000). Requests and Culture: Politeness in British English and Japanese. Berlin: Peter Lang.

[16] Gao, H. (1999). Features of request strategies in Chinese. Working Papers in Linguistics, 47, 73-86.

[17] Ghanbari, H., H. Gowhary \& A. Azizifar. (2015). Investigating apology strategy among Kurdish bilinguals: a case study in Ilam. 
Procedia - Social and Behavioral Sciences, 199, 204-210.

[18] Hassall, T. (2003). Requests by Australian learners of Indonesian. Journal of Pragmatics, 12, 1903-1928.

[19] Hendriks, B. (2008). Dutch English request: A study of request performance by Dutch learners of English. In M. Puetz \& J. Neffvan Aertselaer (Eds.), Developing contrastive pragmatics: Interlanguage and cross-cultural perspectives. Berlin: Mouton de Gruyter, 335-354.

[20] Hong, G. (2005). Research Methodology in Cross-Cultural Pramgatics: An Iquiry into Data Collection Procedures. Beijing: Foreign Language Teaching and Research Press.

[21] Hong, W. (1996). An empirical study of Chinese request stragegies. International Journal of the Sociology of Language, 1, $127-138$

[22] Hu, Z. (2011). Linguistics: a course book (fourth edition). Beijing: Peking University Press.

[23] Kahraman, B. \& B. Akkus. (2007). The use of request expressions by Turkish learners of Japanese. Journal of Theory and Practice in Education, 1, 122-138.

[24] Kasper, G. (Eds.). (1989). Variation in interlanguage: speech act realization. Clevedon: Multilingual Matters.

[25] Kasper, G. (1997). Can pragmatic competence be taught? Honolulu: Second Language Teaching and Curriculum Centre, University of Hawai'i. Retrieved 10 September 2008, from http://nflrc.hawaii.edu/NetWorks/NW06/.

[26] Kasper, G. (2000). Data collection in pragmatics research. In H. Spencery-Oatey, (Eds.), Culturally Speaking: managing rapport through talk across cultures. Continnum, London and New York, 279-303.

[27] Kasper, G. \& K. R. Rose. (2002). Pragamtic development in a sceond language. Oxford: Blackwell.

[28] Koc, E. M. (2011). Politeness in requests: A cross-cultural study of Turkish and British natives. Eurasian Journal of Educational Research, 42, 153-166.

[29] Kotorova, E. (2015). Expressing REQUEST in German and Russian: A communicative-pragmatic field analysis. Procedia Social and Behavioral Sciences, 206, 36-45.

[30] Lee, C. (2005). A cross-linguistic study on the linguistic expressions of Cantonese and English requests. Pragmatics, 4, $395-422$.

[31] Lee-wong, S. M. 1994. Imperatives in requests: direct or impolite--observations from Chinese. Pragmatics, 4, 491-515.

[32] Leech, G. (1983). Principles of Pragmatics. London: Longman.

[33] Li, C. (2009). Chinese EFL learners' pragmtic and discourse transfer in the discourse of L2 request. The University of Hong Kong Ph. D. Dissertation.

[34] Li, W. \& W.-Y. Jiang. (2019). Requests made by Australian Learners of Chinese as a Foreign Language. Journal of Language Teaching and Research, 1, 23-34.

[35] Lin, Y.-H. (2009). Query preparatory modals: Cross-linguistic and cross-situational variations in request modification. Journal of Pragmatics, 8, 1636-1656.

[36] Lin, M.-F. (2014). An interlanguage pragmatic study on Chinese EFL learners' refusal: perception and performance. Journal of Language Teaching and Research, 3, 642-653.

[37] Liu, X. (2014). The study of the Chinese people's inductive inclination in communication. Journal of Language Teaching and Research, 4, 786-790.

[38] Lundell, F. F., \& B. Erman. (2012). High-level requests: A study of long residency L2 users of English and French and native speakers. Journal of Pragmatics, 6-7, 756-775.

[39] Mulken, M. V. (1996). Politeness marker in Dutch and French requests. Language Sciences, 3-4, 689-702.

[40] Phindane, P. (2017). A comparative study of requests amongst second language speakers of English. Journal of Sociology and Social Anthropology, 1, 1-9.

[41] Rafieyan, V., M. Sharafi-Nejad, Z. Khavari, A. Damavand \& S. E. Lin. (2014). Relationship between cultural distance and pragamtic comprehension. English Language Teaching, 2, 103-109.

[42] Rasouli Khorshidi, H. (2013). Study abroad and interlanguage pragmatic development in request and apology speech acts among Iranian learners. English Language Teaching, 5, 62-70.

[43] Rose, K. (1999). Teachers and students learning about request in Hong Kong. In E. Hinkel (Eds.), Culture in second language teaching and learning. Cambridge: Cambridge University Press.

[44] Rue,Y., \& G. Q. Zhang. (2008). Request Strategies: A Comparative Study in Mandarin Chinese and South Korean. America: John Benjamins B. V.

[45] Sabzalipour, B., M. Koosha \& A. Afghari. (2017). Investigationthe effect of colloconstructural corpus-based instruction on pragmalinguistic knowledge of request speech act: Evidence from Iranian EFL students. International Journal of Applied Linguistics \& English Literature, 7, 103-109.

[46] Seyyed, H. T. S., \& M. Mohammad. (2014). Iranian EFL learner's sociolinguistic competence: Refusal strategies in focus. Jounal of Language and Linguistic studies, 2, 48-66.

[47] Schauer, G. A. (2009). Interlanguage Pragmatic Development. Great Britain: Continuum.

[48] Taguchi, N., F. Xiao \& S. Li. (2016). Effects of intercultural competence and social contact on speech act production in a Chinese study abroad context. Modern Language Journal, 4, 775-796.

[49] Thomas, J. (1983). Cross-cultrual pragmatic failure. Applied Linguistics, 2, 91-112.

[50] Warga, M., \& U. Schölmberger. (2007). The acquisition of French apologetic behavior in a study abroad context. Intercultural Pragmatics, 2, 221-251.

[51] Wang, S. (2014). Requests strategies in contemporary Chinese teledramas: A corpus-based study. Chinese Journal of Applied Linguistics, 1, 107-127.

[52] Xie, C., Z. He \& D. Lin. (2005). Politeness: myth and truth. Studies in Language, 2, 431-461.

[53] Ying, J. (2019). The Pragmtic Development of International Students in China. China Social Sciences Publishing House, 102-111.

[54] Yusefi, K., H. Gowhary, A. Azizifar \& Z. Esmaeili. (2015). A pragmatic analysis of thanking strategies among Kurdish speakers of Ilam based on gender and age. Procedia - Social and Behavioral Sciences, 199, 211-217. 
[55] Zhang, Y. (1995). Strategies in Chinese requesting. In G. Kasper (Eds.), Pragmatics of Chinese as native and target language. Honolulu, HI: University of Hawaii Press, 23-68.

Jieqiong Ying was born in Zhejiang, China in 1983. She received her PH. D. degree in Foreign Linguistics and Applied Linguistics from Shanghai International Studies University, China in 2017.

She is currently a lecturer in the School of Foreign Applied Linguistics, Zhejiang International Studies University, Zhejiang, China. Her research interests include interlanguage pragmatics and foreign language education.

Dr. Ying is a member of Hangzhou Institute of Foreign Languages.

Gang Hong was born in Zhejiang, China in 1962. He received his PH. D. degree in Foreign Linguistics and Applied Linguistics from Shanghai International Studies University, China in 2002.

$\mathrm{He}$ is currently a professor in Zhejiang International Studies University, Zhejiang, China. His research interests lie in intercultural pragmatics. He published more than 20 pieces of research articles in Foreign Language Teaching and Research, Modern Foreign Languages, Foreign Language world as well as many academic works.

Prof. Hong is the headmaster of Zhejiang International Studies University, a member of English sub-committee of National Foreign Language Teaching Higher Education Steering Committee, etc. 